\title{
On a New Regularity for Natural Systems Development in the Galimov's Concept of Evolution
}

\author{
VA Dementiev* \\ Institute of Geochemistry and Analytical Chemistry, Russian Academy of Sciences, Russia
}

*Corresponding author: VA Dementiev, Institute of Geochemistry and Analytical Chemistry, Russian Academy of Sciences, Russia

\begin{tabular}{|c|c|}
\hline ARTICLE INFO & ABSTRACT \\
\hline Received: 蔧 February 25, 2021 & \multirow{2}{*}{$\begin{array}{l}\text { Citation: VA Dementiev. On a New Regularity for Natural Systems Development in the } \\
\text { Galimov's Concept of Evolution. Biomed J Sci \& Tech Res 34(2)-2021. BJSTR. MS.ID.005530. }\end{array}$} \\
\hline Published: March 02, 2021 & \\
\hline
\end{tabular}

\section{Introduction}

Publishing a review [1] on the concept of evolution of academician Galimov, the BJSTR journal provided an opportunity for biologists and humanities to look at the general patterns of development in their various fields of knowledge. We consider this to be a great merit of the journal to modern science, which clearly shows a tendency towards interdisciplinary research. At this point "evolution" is used as Galimov had defined it. This is a natural spontaneous process when a part of the material world becomes structurally more complex against the background of general degradation and death.

The review [1] describes the thermodynamic and mechanical conditions that provide the possibility of development in systems of varying complexity - from the molecular world to systems of countries and civilizations. Now the biologist is able to trace the development scenario for living matter from biomolecules to ecosystems, and the humanist is able to compare his forecasts of the development of societies with the scenarios of the micro-world's development. This adds evidence to the predictions. However, the comprehension of the concept of evolution is clearly not complete. Difficult issues remain to be resolved. One such a question sounds like this. The most complex products of social evolution (empire and civilization) sometimes disintegrate into their constituent parts without visible external influences. And after the collapse, they do not show the desire for reunification. At the same time, complex products of biological evolution (organisms and ecosystems) decay only under external adverse influences, as a result of violent death. And then the products of their decay again participate in evolutionary processes. How to explain such a difference in the scenarios of decay, death?
Let's offer a solution to this issue. This can add to the list of conditions for sustainable evolutionary development in any natural system. Diverse natural objects, as a result of attraction-repulsion, form complicated objects. New objects most often have a successful impact on the surrounding worlds and on the original objects. This is the meaning of evolution according to Galimov. Stable unification of dissimilar objects occurs only when the necessary and sufficient conditions are met. One of the conditions is the requirement of comparable structural complexity of the original objects.

Let's take a historical example. Russian civilization, which is noticeably different from other civilizations, has experienced disintegration twice. At the beginning of the 20th century, the Russian Empire collapsed. Soon the forces of mutual attraction gathered this civilization again. The USSR arose. Repulsive forces periodically manifested themselves between the republics, but they did not lead to disintegration. The USSR did not collapse even under an external blow from the Hitlerite European coalition. On the contrary, the Hitlerite coalition collapsed under the blows of the USSR and its allies. Then, due to the rigidity of the control system in the hands of the CPSU, the repulsive forces increased. The USSR has disintegrated, and the free republics show a very weak desire for joint work. Political leaders of Western civilization are pleased to believe that the USSR collapsed under their very weak blows.

In our opinion, the Russian empire was formed due to the desire of the outskirts to associate with the center for the sake of protection from external attacks. The beginning was laid 500 years ago, when a complex system of defense and government was formed in Russia, which consisted of complex institutions (the Tsar and his 
strong State). The outskirts did not develop to the point of creating such institutions. Over time, Russia's concern for the development of the adjoining outskirts led them to a noticeable structuring, to the beginnings of self-government. The Russian Empire collapsed as a result of setbacks in the First World War. The outskirts again began to be attracted to the center for the sake of protection from the quickly restored Russia. In the USSR, the center was much more concerned about the development of the republics than in the Russian Empire. State institutions have emerged in the republics, but they are not completely independent in order to effectively govern their countries. Having freed themselves from Russia, these countries came under external control.

The current state of the system (Russia + close environment) is characterized by a very different degree of complexity of the internal structure of individual parts of the system. In Russia there is again the Tsar and his strong State. In the countries that seceded from Russia, there is a strong dependence of their institutions on Western civilization. Up to a situation when US Vice President Biden was the head of the State Assembly of Ukraine. Due to the abovementioned new evolutionary rule, the evolutionary unification of such objects, different in structure, becomes impossible. To be convinced of the adequacy of this reasoning, it remains to check whether the new evolutionary rule is valid in biopolymer systems. Consider a model system of ready-made molecules of protoporphyrins, polypeptides, and polyenes in a neutral medium containing rare metal atoms. The metal atom easily attaches to any polycyclic molecule. However, this is not an evolutionary process according to Galimov, since the complexities of protoporphyrin and a metal atom are incomparable, and such molecules complicated by a metal are not able to effectively influence either the system itself or the outer worlds. Protoporphyrin readily attaches to a polypeptide or polyene. This is an evolutionary process, as the system becomes more complex. However, the main goal of evolution is not achieved to effectively influence the world. Nature does not remember these complex structures and forgets about them. Genetic memory [2] does not arise.

Now attention! If a $\mathrm{Mg}$ atom is accidentally inserted into a protoporphyrin molecule, a complex heme structure will arise, which will willingly attach to a peptide-other-fourth, and hemoglobin can be obtained. It is not for me, a physicist, to convince a biologist what an important role this compound plays in the world of living beings. And Nature will remember this fact forever. If a FeII atom is accidentally inserted into a protoporphyrin molecule, a complex structure will arise that is ready to join the polyene. Chlorophyll will be generated. Nature will also remember this news because of its usefulness. And the great Russian biologist Timiryazev will write an article "The Cosmic Role of the Green Leaf." However, disruptions in the formation of genetic memory are possible. The Lathraéa plant has failed to create the protein structures that guide chlorophyll synthesis. Therefore, Lathraéa lives a miserable existence as a parasite.

\section{References}

1. VA Dementiev (2020) Regularities of Evolution from Biopolymers to Social Systems. Biomedical Journal of Scientific \& Technical Research 32(1).

2. VA Dementiev (2020) The Formation of Genetic Memory at Various Stages of the Evolution of the Earth. Journal of Current Trends in Physics Research and Applications 1(1): 107.

\section{ISSN: 2574-1241}

DOI: 10.26717/BJSTR.2021.34.005530

VA Dementiev. Biomed J Sci \& Tech Res

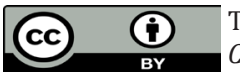

This work is licensed under Creative Commons Attribution 4.0 License

Submission Link: https://biomedres.us/submit-manuscript.php

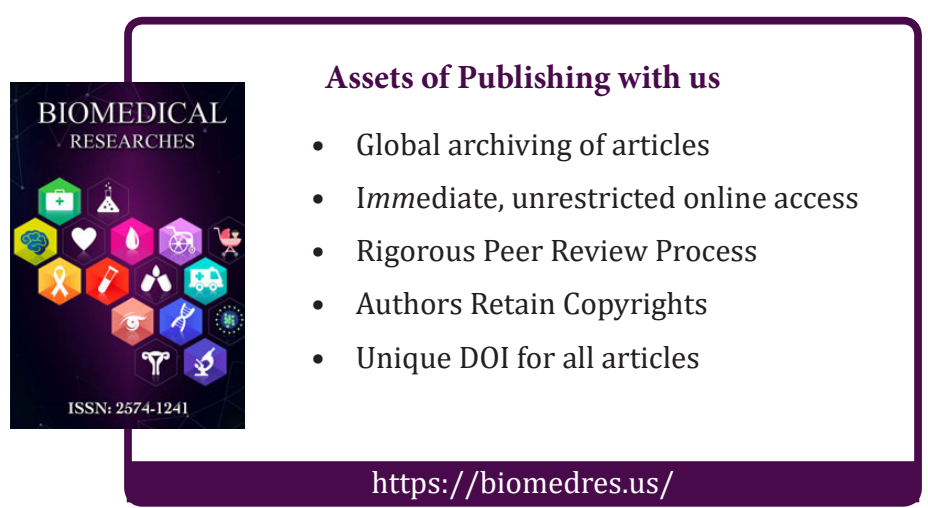

